Síntese - Rev. de Filosofia

v. 38 N. 120 (2011): 91-115

\title{
AS CRÍticas HEIDEGgerIaNAS AO STATUS FILOSÓFICo DA CONSCIÊNCIA EM HUSSERL DIANTE da PROBlemática do CONHeCmento do SÉCULO XIX
}

(Heideggerian criticisms of the philosophical status of consciousness in Husserl regarding the issue of knowledge in the 19th century)

José Fábio da Silva Albuquerque *

Resumo: Neste artigo apresentamos as críticas que Heidegger direciona à consciência pura em Husserl como horizonte específico e primeiro da filosofia. Com a finalidade de dar uma resposta à crise na Filosofia ocorrida no século XIX e, consequentemente, estabelecer os parâmetros para o conceito científico, Edmund Husserl - combatendo o Psicologismo e o Neokantismo - apresenta a Fenomenologia enquanto ciência rigorosa e os atos da consciência transcendental como o campo de sua investigação. Heidegger, por sua vez, radicaliza a corrente fenomenológica e critica esse status da consciência pura como uma permanência de Husserl sob o influxo dos preconceitos da filosofia moderna.

Palavras-chave: Heidegger, Husserl, Fenomenologia, Ciência Moderna, Psicologismo.

Abstract: This paper aims at presenting the criticisms that Heidegger addresses to Husserl's pure consciousness, understood as the primary specific horizon of philosophy. In order to answer the crisis of 19th century Philosophy and, consequently, establish parameters for the scientific concept, Edmund Husserl combating Psychologism and Neokantism - presents Phenomenology as a rigorous

\footnotetext{
* Doutorando - Universidade Federal da Paraíba (programa integrado UFPB-UFPEUFRN). Artigo submetido a avaliação no dia 01/09/2010 e aprovado para publicação no dia 27/01/2001.
} 
science and the acts of transcendental consciousness as his field of research. Heidegger, in turn, radicalizes the phenomenological trend and criticizes the status of pure consciousness as Husserl's continuance under the prejudices of modern philosophy.

Keywords: Heidegger, Husserl, Phenomenology, Modern Science, Psychologism.

\section{1 - As mudanças sofridas no conceito de ciência}

A

pós a morte de Hegel (1831), o conceito de ciência predominante na Alemanha passa por inúmeras modificações, tanto no que diz respeito a sua estrutura como também acerca de suas funções. Levando-se em consideração a visão sistemático-absoluta do idealismo hegeliano, qualquer conhecimento só poderia ser considerado autenticamente científico caso pertencesse - e, portanto, estivesse subordinado - ao poder do Conceito que tudo engloba. A exposição conceitual do conteúdo era o critério fundamental no sistema hegeliano para o status de ciência. Nesse sentido, a noção de científico encontra-se intrinsecamente relacionada com horizonte filosófico. No entanto, a partir da morte desse alemão que tanto influenciou o pensamento europeu, uma recusa cada vez maior à visão sistemática do idealismo absoluto se faz presente, desencadeando o desenvolvimento de ciências particulares que buscam uma autonomia diante do pensamento filosófico unificador.

Podemos averiguar então, que a partir do momento em que a filosofia tornou-se problemática sobre sua própria identidade e justificação - exemplo disso foi a própria luta entre os hegelianos de direita e os hegelianos de esquerda -, a perspectiva do que seja considerado ciência também necessitou trilhar o mesmo caminho de redescobrimento. Desta forma, a crise na filosofia pós-hegeliana implica no problema fundamental do genuíno significado da ciência, como também de seus possíveis resultados e descobertas. O conceito de científico pós Hegel desvencilha-se progressivamente do conceito de filosófico - visto que a ciência deixa de vincular-se à estrutura englobante do sistema absoluto - e passa a representar um padrão de investigações independentes que não possui o intuito de abarcar todo o real com "um único golpe de vista". A totalidade se mostra, portanto, como uma ilusão metafísica, em relação à qual o verdadeiramente científico tenta de todas as formas se afastar. Para o período do século XIX posterior a Hegel o termo "conhecimento" torna-se sinônimo de conhecimento do particular.

Instaura-se mais uma vez e de forma crítica a tensão entre ciência e filosofia. Na visão de Hans-Georg Gadamer ${ }^{1}$, entretanto, a filosofia e a ciência

${ }^{1}$ GADAMER, H. G.. Los fundamentos filosóficos del siglo XX. In La secularización de la Filosofía: hermenêutica y posmodernidad. Barcelona: Editorial Gedisa, 1994, p. 91. 
encontram-se em choque desde o século XVII, a partir do problema de uma possível unificação da ciência moderna (enquanto novo fundamento das atitudes humanas acerca do mundo) com o pensamento filosófico herdado dos gregos. De qualquer maneira, o fator específico dessa tensão na segunda metade do século XIX é que a filosofia agora se encontra tanto ameaçada pelo método científico como também incerta sobre sua própria possibilidade de "cientificidade". Enquanto a noção de ciência pós-hegeliana vai encontrar predominantemente seu fundamento de cientificidade na eficácia empírica das chamadas "ciências naturais", a filosofia enfrenta, por sua vez, o "destronamento" de seu status científico, visto não parecer mais capaz de uma interpretação sistemática da realidade. Nessa época o método científico parece demonstrar, com cada vez mais confiança, o quanto a tradição filosófica sempre esteve perdida em especulações abstratas.

Essa suspeita acerca da justificação da Filosofia como modelo de conhecimento "objetivo" advém do fato de ela (em comparação com a ciência) não ter desenvolvido um âmbito seguro (correlacionado a um método) apto a lhe garantir a universalidade encontrada, por exemplo, nos resultados das experiências químicas e físicas. Essas ciências particulares demonstraram a possibilidade de se alcançar uma universalidade, não através de uma pretensa apoditicidade desvinculada de qualquer experiência (como era tomado pelo conceito clássico de ciência), mas, pelo contrário, através de experiências procedimentalmente rigorosas. A experiência metodologicamente guiada passa, portanto, a ser considerada o verdadeiro critério (fundamento) científico do conhecimento, e não mais uma fonte de informações para a filosofia-ciência.

Com esse termo [empirização] se quer nomear o processo que fez do empirismo uma característica definitória da ciência real. Prescindindo das chamadas ciências formais, quer dizer, da matemática dentro de uma interpretação formalista, "ciência" é sinônimo de "ciência empírica". Não quer isso dizer que qualquer experiência que não seja científica esteja em condições de estabelecer se um conhecimento o é; de fato, resulta impossível definir o que se entende por "científico" nesse contexto, mediante exemplos que só se verificam na própria experiência. Porém, tampouco é a ciência, entendida como sistema de asserções ou conjunto de conhecimentos, o que faz possível qualificar de científica uma experiência; só o procedimento mediante o qual um saber se adquire e se verifica (procedimento que, em si mesmo, se entende como científico) permite afirmá-lo. O essencial do procedimento empírico é a investigação, e a ciência que se caracteriza por este procedimento é, fundamentalmente, ciência-investigação. Nessas condições, quando a experiência se considera um critério científico em si mesmo, o procedimento se converte em uma forma de identidade. ${ }^{2}$

\footnotetext{
${ }^{2}$ SCHNÄDELBACH, Herbert. Filosofía en Alemania: 1833-1933. Madrid: Cátedra, 1991, pp. 106-107.
} 
A ciência passa a significar, portanto, um procedimento metodologicamente orientado que encontra na experimentação o seu fundamento de defesa. Ela não é mais um mero "sistema de asserções ou conjunto de conhecimentos" como sempre foi concebida em construções fundacionistas do saber; não se pode mais simplesmente partir de axiomas abstratos com a função de fundamentar o desenvolvimento especulativo de outras proposições que, por sua vez, pretensamente justificariam os próprios axiomas dos quais são oriundos. Ela também não pode cair em uma sucessão de experiências desprovidas de organização para fundamentar sua cientificidade. Desta forma, é o próprio procedimento entendido como científico que emprestará o seu caráter a um determinado conhecimento, sempre adquirido, por sua vez, através da prova da experiência.

Essas mudanças na estrutura do conceito de ciência no século XIX acarretam uma dinamização sem precedentes no conhecimento científico, pois agora ele não possui mais nada de esotérico e o seu desenvolvimento não está mais restrito à imagem do "gênio" que personaliza a ciência como produto de uma individualidade; com a identidade da ciência enquanto procedimento e investigação é uma massa de investigadores - onde suas individualidades são completamente substituíveis - que se torna o verdadeiro sujeito do desenvolvimento científico.

A ciência baseada na investigação, [...] fundamentalmente caracterizada pela inovação e pelos processos impessoais, é o resultado da dinamização do antigo conceito de ciência, secularmente aceito desde Aristóteles a Hegel. Os elementos mais importantes da mudança foram a empirização e a temporalização, tanto em relação ao objeto de sua competência como à forma do conhecimento científico. ${ }^{3}$

O conhecimento agora se manifesta em uma nova "estrutura", não no sentido de um conjunto coeso de informações que presumivelmente trataria da totalidade das coisas, mas no sentido de uma nova localização na relação humana com o mundo. Nessa nova estrutura encontramos uma dupla temporalização. A primeira diz respeito ao seu objeto, pois ele não é mais vinculado a uma verdade absoluta e, portanto, eterna. O conhecimento científico pós-Hegel sempre diz respeito a um momento histórico específico da investigação e, portanto, sempre estará suscetível de uma posterior implementação - o conhecimento do objeto sempre será contingente e passível de acréscimos ou de revogações. A segunda temporalização refere-se, por sua vez, à forma do conhecimento científico, pois este sempre se apresentará vinculado a determinados procedimentos e instrumentos de pesquisa, o que sempre abre a possibilidade de investigar o objeto diante de outras condições de análise.

${ }^{3}$ SCHNÄDELBACH, Herbert. Filosofía en Alemania: 1833-1933. Madrid: Cátedra, 1991, p. 93. 
Pois bem, diante desse contexto e em um momento de forte tendência positivista no qual toda a realidade é tomada a partir de dados empíricos, algumas problemáticas que sempre se encontraram na esfera das questões filosóficas também acabam por se desenvolver em um horizonte de pesquisa cientificista. Umas das principais questões que se enquadram nessa descrição são a de como é possível conhecer os objetos e, consequentemente, como é possível a validação de tais conhecimentos. E como a efetivação do conhecimento é dada na consciência, então a própria vida psíquica deve ser investigada cientificamente. A consciência, desta forma, não pode mais ser tomada no sentido especulativo da filosofia hegeliana, ela agora é uma estrutura empírica que deve ser investigada empiricamente. Isso desemboca na convicção de que é através das experiências procedimentais das ciências naturais que se encontrará o fundamento e os correlatos aspectos de validação do conhecer.

Onde reina uma mentalidade positivista, é natural que a Psicologia experimental se arvore em intérprete exclusiva dos fenômenos da consciência. A sua rápida penetração em todos os setores da cultura justifica o título de ‘Era da Psicologia' dado a esta época. Os métodos da nova ciência são empregados então em grande escala não só na Literatura e nas Artes, na Pedagogia e no Direito, mas também na explicação da natureza da Moral, da Estética, da Religião, da Linguagem e, sobretudo, do conhecimento e da verdade. A interpretação da verdade através das causas psíquicas, responsáveis pela efetuação do juízo, chama-se Psicologismo. ${ }^{4}$

O psicologismo - que não passa de um desdobramento do naturalismo então predominante - defende e se aventura no estudo empírico dos mecanismos psicológicos como meio de formular a gênese do processo de conhecimento. Ou seja, a partir da investigação empírica dos atos psicológicos se pretende chegar à explicação da condição de possibilidade do conhecer. Essa concepção acabou manifestando-se como uma considerável ameaça dentro do campo das chamadas humanidades, visto que a psicologia pretendia se basear exclusivamente em um método vinculado à pesquisa das ciências naturais e tomar como critérios os aspectos comportamentais dos indivíduos, o que exigiria um rompimento com a recém estabelecida divisão entre ciências da natureza e ciências do espírito.

Por sua vez, em um caminho de oposição a essa postura materialistaempírica do psicologismo, desenvolve-se, também na segunda metade do século XIX, um movimento que representa uma tentativa de renovar a filosofia diante das circunstâncias históricas relacionadas com a inovadora dimensão das ciências. É o movimento filosófico conhecido como Neokantismo.

\footnotetext{
${ }^{4}$ MAC DOWELL, João A. A. A. Gênese da Ontologia Fundamental de M. Heidegger. São Paulo: Loyola, 1993, p. 28.
} 
Essa transformação [da consciência científica] permite-nos compreender o modo no qual uma nova tentativa foi feita no curso da segunda metade do século XIX para trazer a filosofia científica para si mesma. Essa tentativa aconteceu na tendência de conceder às ciências particulares seu direito independente e ao mesmo tempo assegurar à filosofia seu próprio campo em relação a essas ciências. Isso conduz a uma filosofia que tem o caráter essencial de uma teoria da ciência, uma lógica das ciências. Esse é o primeiro aspecto distintivo da renovação filosófica na segunda metade do século XIX. [...] O segundo aspecto é que a renovação toma lugar não em um retorno original às coisas em questão, mas retorna a uma filosofia historicamente estabelecida, a de Kant. A filosofia é então tradicionalista; ela assume um complexo bem definido de uma linha bem definida de questionamento e, por sua vez, chega a uma posição bem definida em relação às ciências concretas. $^{5}$

Assim, o Neokantismo vê no resgate do pensamento kantiano - através da leitura exclusivamente epistemológica da Crítica da Razão Pura - uma alternativa para estabelecer a validação do conhecimento e da verdade a partir da imanência das categorias, sem, contudo, voltar a cair no absolutismo dos idealismos fichteano, schellingiano e hegeliano. Segundo Gadamer $^{6}$, essa leitura teórico-epistêmica de Kant torna-se possível, e até certo ponto justificada, ao se levar apenas em consideração outro escrito kantiano - os Prolegomena -, o qual apresenta uma versão simplificada das ideias fundamentais da Crítica da Razão Pura e parece apresentar o fato das ciências como algo que deva ser pressuposto; essa pressuposição, por sua vez, implica que a crítica de Kant mostra-se apenas como veículo justificador do fato científico.

Diante da invasão e do sucesso das ciências particulares nos vários ramos do conhecimento, o neokantismo tenta recolocar a filosofia em um estágio anterior ao procedimento científico, estabelecendo-a como uma teoria ou lógica da ciência. Desta forma, o neokantismo visualiza - através das categorias imanentes - uma investigação das estruturas das ciências particulares, preservando os direitos intrínsecos das mesmas ao mesmo tempo em que ainda lança, diante das novas especificidades históricas, uma tarefa relativamente autônoma para a filosofia. Ele coloca-se, de uma forma geral, em posições diversas ao psicologismo positivista, embora alguns dos seus representantes também tenham caído numa interpretação psicológica da Crítica da Razão Pura ${ }^{7}$. Isso não quer dizer, por sua vez, que essa corrente

${ }^{5}$ HEIDEGGER, Martin. History of the Concept of Time - Prolegomena. Translated by Theodore Kisiel. Bloomigton, Indiana: Indiana University Press, 1992, p. 13.

${ }^{6}$ GADAMER, H. G. La Razón en la Época de la Ciencia. Barcelona: Alfa, 1981, p 95.

7 Entre os filósofos neokantianos que desenvolveram uma interpretação psicológica da origem do conhecimento exposta na Crítica da Razão Pura, encontram-se Fries e Herbart. Contra essa tendência psicologista de interpretar Kant, podemos citar os nomes de neokantianos como Cohen e Natorp da Escola de Marburgo, ou Windelband e Rickert da Escola de Baden. A esse respeito ver MAC DOWELL, A Gênese da Ontologia Fundamental de M. Heidegger, capítulo I. 
aceitou todas as posturas kantianas acerca da questão do conhecimento, pois, caso isso acontecesse, ela seria forçada a reconhecer a necessidade da experiência na formação do que Kant considera, em sentido estrito, o conhecer. Para o Neokantismo, qualquer alusão a uma premissa material do objeto de conhecimento (premissa científica) é rechaçada, pois denotaria características metafísicas desnecessárias e negativas.

"Uma filosofia estritamente transcendental" exige que não se estabeleça uma concepção material prévia do objeto de conhecimento.[...] Unicamente os pontos de vista relacionados com a lógica da formação do conceito e a formação dos juízos são admissíveis para os neokantianos em uma teoria do conhecimento. O que em Kant se chamou "razão pura" se estabelece agora só como o objeto de uma lógica estritamente formal do conhecimento. ${ }^{8}$

A partir de tais movimentos podemos conceber, em linhas gerais, a mudança que o conceito de ciência sofreu no decorrer do século XIX, principalmente a partir da morte de Hegel. A fragmentação experimentada nos mais variados campos do conhecimento; a dinamização representada pela empirização e temporalização da atitude científica; o surgimento da experiência procedimental como critério de cientificidade; o rechaço dos movimentos nascentes com qualquer tipo de vinculação aos conceitos metafísicos; eis alguns dos aspectos que determinaram a referida mudança e que propiciaram o surgimento de novos questionamentos e o nascimento de novas posturas acerca da significação de filosofia, assim como das relações que esta pode manter com o pensamento científico.

\section{2 - O projeto husserliano de uma filosofia como ciência rigorosa}

É nesse horizonte de fragmentação do conhecimento em diversas ciências particulares - no qual a experiência é tomada como critério científico; da oposta tentativa neokantiana de explicação estritamente formal de um conhecimento que não se vincula com nem diz nada acerca do mundo; da corrente psicologista que defende a explicação das condições de possibilidade do conhecimento e de sua validação através dos atos psicológicos, que surge a figura de Edmund Husserl. Colocando-se entre os pensadores que rechaçam a experiência como critério para o alcance do conhecimento científico, Husserl identifica-se nessa disputa sobre a validação dos critérios científicos com a visão clássica (Aristotélica) de ciência. Também adota a vertente da interpretação pós-materialista (ou fenomenológica) do mun-

\footnotetext{
${ }^{8}$ SCHNÄDELBACH, Herbert. Filosofía en Alemania: 1833-1933. Madrid: Cátedra, 1991, pp. 74-75.
} 
do físico, segundo a qual a física consistiria em uma descrição dos fenômenos observáveis, encontrando, assim, uma terceira alternativa entre o naturalismo positivista e o transcendentalismo vazio dos neokantianos. Muito embora a visão fenomenológica da natureza tenha surgido como uma vertente da própria empirização da ciência - já que esta elimina qualquer noção de essencialismo como preconceito metafísico e se desenvolve exclusivamente a partir de observações dos fenômenos - ela acabou perdendo seu espaço na corrida para determinar os critérios que demarcassem o âmbito científico ao se confrontar com a teoria atomista e suas comprovações empíricas ${ }^{9}$.

Por possuir uma formação predominantemente matemática, Husserl não dirige, a princípio, nenhum grande interesse pela filosofia. Só após o encontro com Franz Brentano o rumo de seu pensamento é redirecionado, e esse episódio acabaria por marcar decisivamente os desdobramentos da filosofia no começo do século XX:

Husserl era originalmente um matemático. Ele foi um estudante de
Weierstrass e escreveu uma dissertação matemática para [obter] seu grau. O
que ele ouviu de filosofia não ia além daquilo que qualquer estudante ad-
quiria nas lições. [...] Foi apenas depois de graduado [doutorado] que Husserl
assistiu os cursos do homem que era então muito discutido. A paixão de
Brentano pelo questionamento e pela reflexão impressionou Husserl tão
fortemente que ele permaneceu com Brentano por dois anos, de 1884 a 1886 .
Brentano forneceu o giro decisivo para a direção científica que o trabalho de
Husserl tomou. A sua oscilação entre matemática e filosofia foi resolvida.
Através da impressão que Brentano, como professor e investigador, fizera
sobre ele, Husserl descobriu, dentro das filosofias improdutivas da época, a
possibilidade de uma filosofia científica. ${ }^{10}$

O projeto que Husserl se impõe após os anos de aprendizado com Brentano diz respeito à formulação de uma filosofia científica. Não se igualava, portanto, ao neokantismo, que tendia a uma filosofia da ciência, como se ela (a filosofia), após o advento do método científico, não pudesse mais atuar a não ser como uma espécie de crítica ou teoria do conhecimento e se restringisse a examinar as estruturas a priori deste último. Husserl busca, por sua vez, um fundamento que garanta um conhecimento apodítico para a filosofia, tornando-a uma ciência rigorosa e até mesmo a mais rigorosa de todas as ciências, ou mais precisamente, a ciência das ciências. Essa questão da validação do conhecimento apodítico em Husserl está ligada, portanto, ao horizonte mais amplo da disputa que perdurou durante todo o século XIX sobre os critérios que deviam determinar o status científico do conhecimento.

${ }^{9}$ A corrente fenomenológica das ciências empíricas ganha notoriedade principalmente com a produção de Ernst Mach.

${ }^{10}$ HEIDEGGER, Martin. History of the Concept of Time - Prolegomena. Midland book ed., 1992, p. 23. 
O primeiro passo de Husserl para seu objetivo foi descartar a experiência empírica - mesmo que procedimental - como critério de cientificidade. $\mathrm{O}$ conhecimento apodítico necessário para a universalidade científica não pode advir de processos empíricos, pois a partir destes só uma relativa generalidade pode ser alcançada ${ }^{11}$. Assim, rechaçando a empirização ocorrida nas ciências e não podendo mais se valer de especulações de tipo hegelianas para fundamentar os conhecimentos de sua filosofia científica, Husserl encontrará nas ciências matemáticas ${ }^{12}$ a inspiração necessária para a criação de uma alternativa viável ao seu projeto. Mas qual a especificidade que Husserl encontrou na ciência matemática que o fez considerá-la, até certo ponto, um modelo para o seu projeto filosófico? $\mathrm{O}$ fato de que, ao contrário das ciências empírico-descritivas, nessas ciências matemáticas o conhecimento já encontrar seu ponto de partida em um nível categorial, ou seja, de idealidade.

Ciências teoréticas e exatas como Aritmética, Geometria, Mecânica Analítica, Astronomia Matemática, Ótica Teorética, e Física Teorética em geral provêm exemplos de teorias no sentido estrito [...]. O que é mais significativo em tais teorias não é sua habilidade em explicar fatos particulares, por exemplo, a astronomia matemática em relação aos fatos da gravitação, mas seu caráter como sistemas fechados de leis ideais no qual uma ou várias são fundamentais e das quais todas as outras são deduzíveis. É realmente este caráter nomológico desses sistemas que provém a base para a explicação a priori dos possíveis fatos, incluído dentro deles e que lhes dá seu poder explanatório. De fato, antes de começar com instâncias particulares, como as ciências descritivas, a exemplo do que a História e a Geografia fazem, as ciências nomológicas começam imediatamente no nível categorial. A Geometria, por exemplo, antes de descrever as inúmeras formas disponíveis através da intuição sensorial, começa com alguns construtos fundamentais como corpo, superfície, ponto, e ângulo, dos quais ela formula seus axiomas ou "primitivas leis de essência", das quais são então deduzidas leis e essências que em geral são estranhas a nossa intuição direta. ${ }^{13}$

Essas ciências de cunho matemático não tratam em primeiro lugar de um domínio factual, mas elevam-se como sistemas formais exemplares que possuem um grupo definido de axiomas e, a partir destes, conseguem definir uma teoria formal acerca da multiplicidade material do respectivo domínio objetivo, ou seja, define a forma dessa multiplicidade a partir de categorias formais. O caráter de idealidade das ciências de cunho matemá-

11 Cf. KOCKELMANS, Joseph J.. The Mathematization of Nature in Husserl's Last Publication - Krisis. In: Phenomenology and the Natural Sciences - Essays and Translations. Evanston: Northwestern University Press, 1970, p. 57.

${ }^{12}$ KISIEL, Theodore J.. Phenomenology as the Science of Science. In: Phenomenology and the Natural Sciences - Essays and Translations. Evanston: Northwestern University Press, 1970, p. 18.

${ }^{13}$ KISIEL, Theodore J.. Phenomenology as the Science of Science. In: Phenomenology and the Natural Sciences - Essays and Translations. Evanston: Northwestern University Press, 1970, pp. 18-19. 
tico também é visto positivamente por Husserl por sua capacidade de abarcar os mais variados domínios objetivos, o que estabelece parentescos estruturais entre as mais variadas teorias que, a primeira vista, não passavam de construções isoladas acerca da heterogeneidade de seus conteúdos concretos. Tomemos como exemplo o símbolo "+". Esse símbolo, ao contrário do que se pensaria a princípio, não representa necessariamente a adição de números, mas fundamentalmente uma operação formal determinada pelas propriedades de comutatividade e associatividade, na qual os objetos ideais submetidos a ela não precisam ser numerais, mas qualquer objeto que seja capaz de se submeter a essa operação formal. É nisso que se encontra a força do nível formal, pois torna possível o parentesco entre as teorias e mesmo entre ciências inteiras, possibilitando assim o vislumbre do surgimento de uma ciência das ciências, de um sistema dos sistemas.

No entanto, isso não significa que, simplesmente a partir do que já foi exposto, possamos caracterizar o pensamento de Husserl de transcendental; ele defende que, para precaver-se de cair em um mero jogo de símbolos vazios de significado, ou o que ele chamará de Sinnentleerung, é necessário que as categorias formais estejam vinculadas ao solo intuitivo do qual elas recebem seu fundamento.

Todo sistema formal, não importa o quanto distante pode parecer estar dessas raízes, é ainda uma forma possível de teorias reais. Pois mesmo embora uma cópia ontológico-formal viva apenas em suas formas teoréticas, ela ainda possui sua relação com a ontologia do mundo do qual retira seus axiomas "autoevidentes" e primeiras premissas. Uma cópia formal é apenas uma "semirregião" que ainda possui as marcas de seu tosco desenho na região real. ${ }^{14}$

Só quando estão vinculadas ao mundo concreto que sempre nos é dado previamente, as teorias mantêm o seu direito de reivindicar objetividade. A pergunta que agora tem que ser respondida é: qual o mecanismo método - que permitirá uma investigação de nível formal sem perder o contato com o mundo concreto do qual qualquer teoria tem de estar vinculada? É nas análises sobre os procedimentos de Galileu que Husserl também encontrará a resposta a essa questão fundamental, pois na matematização da natureza executada por aquele podemos encontrar o fundamento científico que, embora se encontre no nível formal, está justificadamente vinculado ao mundo real ${ }^{15}$.

\footnotetext{
${ }^{14}$ KISIEL, Theodore J.. Phenomenology as Science of Science. In: Phenomenology and the Natural Sciences - Essays and Translations. Evanston: Northwestern University Press, 1970 , p. 21.

15 Devemos levar em consideração as observações de Kockelmans e Gurwitsch de que, quando Husserl fala de "Galileu" ou de "ciência de Galileu" ele não se refere exclusivamente à pessoa histórica Galileu nem aos trabalhos científicos historicamente desenvolvidos por ele, mas sim às particularidades daqueles procedimentos inaugurados por Galileu que se desenvolveram por todo o século XVI e que hoje conceituamos de "ciência moderna".
} 
Por causa da subjetividade e relatividade das qualidades secundárias, a ciência não pode aceitar o mundo que nós percebemos como válido e, então, deve tentar encontrar o invariável, o eterno, a estrutura matemática que está contida e escondida no mundo real como ele nos é imediatamente dado na percepção. Penetrar através do véu das aparências e então descobrir a estrutura matemática do mundo, descobri-lo como uma cópia matemática, é precisamente a tarefa da ciência como Galileu a concebe. ${ }^{16}$

Husserl acredita que identificando o que movimenta tal objetivo, ou seja, aquilo que está pressuposto na postura de Galileu da matematização da natureza, encontrará o critério que servirá de fio condutor para a construção de sua ciência das ciências. Se a postura de Galileu desencadeou todo o movimento das ciências modernas, então descobrindo o fundamento dela descobrirá o próprio fundamento científico. Alcançada essa meta poderá ser respondida, enfim, a pergunta que vem sendo colocada na Alemanha desde a morte de Hegel: o que dá o caráter de cientificidade à ciência?

Qual a particularidade da concepção de física de Galileu, o que a movimenta? A resposta: a noção de uma geometria como ciência de entes ideais que, no entanto, sempre pode ser aplicada ao mundo encontrado nas experiências imediatas. A inovação de uma descrição e análise matemática dos fenômenos foi o que conduziu Galileu à formulação das leis da mecânica. Galileu submeteu a natureza a uma construção matemática e, a partir disso, pôde construir um novo conceito de lei natural. É a abstração dos fenômenos e sua verificação através do contar, medir e pesar que possibilitam a investigação no âmbito das ciências naturais. Portanto, a noção de uma geometria aplicada é a grande inovação do procedimento de Galileu. Deste modo, é no fundamento dessa aplicabilidade da geometria que Husserl direcionará sua atenção.

Está claro que indo da perfeição realizável na pratica até o horizonte da perfeição imaginável, formas limites começam a delinear-se - invariantes e inalcançáveis pólos em direção aos quais uma perfeição posterior continua apontando. É a tarefa da geometria estar interessada naquelas formas ideais, determinar sua caracterização ideal, e, iniciando daquelas que já estão disponíveis, continuamente construir novas formas e figuras. De fato, da "práxis" real que está sempre limitada ao que é possível na prática (e que lida com o real e com corpos empíricos realmente possíveis), nós temos agora uma "práxis idealizante" que se limita exclusivamente ao domínio das formas limites puras. Em outras palavras, na visão de Husserl a "origem" da geometria é para ser encontrada na idealização e construção. ${ }^{17}$

\footnotetext{
${ }^{16}$ KOCKELMANS, Joseph J.. The Mathematization of Nature in Husserl's Last Publication - Krisis. In: Phenomenology and the Natural Sciences - Essays and Translations. Evanston: Northwestern University Press, 1970, p. 52.

${ }^{17}$ KOCKELMANS, Joseph J.. The Mathematization of Nature in Husserl's Last Publication - Krisis. In: Phenomenology and the Natural Sciences - Essays and Translations. Evanston: Northwestern University Press, 1970, p. 54.
} 
A idealização, ou ideação, é o fundamento da geometria aplicada de Galileu e aquilo que dá a condição de possibilidade para desenvolver uma ciência formal que possa direcionar-se ao mundo. Quer dizer, alcançar na multiplicidade do mundo vivido as ideações a partir das quais se poderá alcançar "leis", conhecimentos objetivamente válidos que escapem ao subjetivismo e relativismo das percepções imediatas.

O projeto de Husserl, no entanto, não é desenvolver (como foi o projeto de Galileu) teorias acerca de conhecimentos específicos, mas uma filosofia enquanto ciência apodítica que, mesmo possuindo um campo exclusivo de investigação, também haveria de servir de fundamento e justificação para quaisquer ciências particulares. No entanto, qual o ponto de partida através do qual essa filosofia científica poderia ser formada? Justamente o fenômeno que se mostra como o mais imediato possível para a construção de qualquer conhecimento: a espontânea correlação da consciência com aquele mundo vivido que, como vimos, sempre se manifesta como o fundamento objetivo de qualquer categorização formal do intelecto. Nessa espontânea correlação, a consciência admite como seguros e reais tanto o mundo exterior a si como ela mesma. É a "tese" da transcendência do mundo que se manifesta como atitude natural. Pois bem, é precisamente partindo dessa espontânea correlação da atitude natural que Husserl pretende alcançar e traçar um novo horizonte filosófico - inalcançável às ciências positivas - que se mostre como uma região de domínio especificamente fenomenológico. Determinando esta região como a própria natureza intencional da consciência, essa última deve ser trazida à luz a partir do método fenomenológico - processo de ideação que possibilita a formação de uma investigação apoditicamente justificada.

A intencionalidade foi definida como a estrutura das experiências vividas, isto de acordo com os momentos básicos de sua constituição, intentiointentum. A elaboração de seu a priori requer a exposição das estruturas que com antecedência constituem os comportamentos individuais e seus possíveis contextos, aqueles que já se encontram em toda percepção e em todo percebido, indiferentemente de como a percepção enquanto percepção está concretamente individualizada nos homens particulares, ou em sua proveniência e forma. Esse discernimento do a priori é chamado ideação. Ideação é um ato de intuição categorial, isto é, um ato fundado na visão a priori de uma individuação concreta. ${ }^{18}$

Enquanto as ciências empíricas - mais especificamente o psicologismo defendiam os acontecimentos da consciência empírica como sendo o fundamento para o surgimento e validação do conhecimento, Husserl defenderá que só no nível da idealidade das experiências vividas é possível alcançar o fundamento necessário para a construção de uma ciência. De

${ }^{18}$ HEIDEGGER, Martin. History of the Concept of Time - Prolegomena. Midland book ed., 1992 , p. 95. 
acordo com projeto fenomenológico de Husserl, é a partir das análises das estruturas a priori dos comportamentos da consciência, cuja totalidade ele designa como fluxo de experiências vividas, que será possível alcançar conhecimentos válidos. Tais estruturas são os atos da consciência. Portanto, o peculiar das análises fenomenológicas de Husserl é o fato de que agora são os próprios atos da consciência que devem ser investigados. A investigação fenomenológica não se preocupa em saber como vivenciamos factualmente os objetos apresentados em sua correlação com a consciência, mas sim como se dão os próprios atos; refletir para a fenomenologia husserliana é deixar de vivenciar os objetos apresentados na atitude natural e voltar-se, vivenciar tematicamente, os próprios atos das experiências vividas.

Assim, quando estou refletindo em direção a uma experiência particular, a um ato particular tal como aquele de perceber uma coisa, eu estou tematicamente focado sobre a percepção e não sobre o percebido. Naturalmente eu posso tornar a percepção mesma o tema, de forma que o percebido, o que a percepção percebe, seu objeto, esteja mesmo coapreendido, mas de tal modo que eu não vivo diretamente na percepção, diga-se, da cadeira, mas antes vivo tematicamente na apreensão do ato perceptivo e do que é percebido nele. Esse modo de considerar o ato e seu objeto não é uma apreensão transcendente da coisa mesma. Considerando a reflexão nesse modo, eu, até certo ponto, "não vou junto com" a percepção concreta, para colocar no vernáculo. Eu não vivo realmente na percepção da cadeira, mas na atitude da apreensão reflexiva imanente do perceber a cadeira, não na tese do mundo material, mas na posição temática do ato de perceber a percepção e de seu objeto como ele está ali no ato. Esse não "indo junto com" a tese do mundo material e de todo mundo transcendente é chamado e)poxh/, suspensão. ${ }^{19}$

Dessa forma, está determinada a nova região filosófica concernente às investigações fenomenológicas: a região da pura consciência com seus respectivos correlatos. Husserl supera, assim, as dificuldades encontradas nas questões acerca do commercium entre uma consciência capacitada a conhecer e os objetos transcendentes a essa consciência. Essa última postura faz parte da atitude natural, a qual foi superada quando se deixou de se preocupar demasiadamente com as coisas do mundo para ocupar-se das próprias estruturas a priori dos comportamentos da consciência (os atos da consciência) e do modo como seus objetos são apresentados. É o primeiro estágio do método fenomenológico - a redução transcendental. Husserl não faz, portanto, uma pura fenomenologia dos atos ou uma pura fenomenologia dos objetos; mesmo havendo a separação desses dois elementos nos termos de noesis (enquanto estrutura específica do direcionarse-a...) e noema (enquanto objeto sendo intencionalizado no ato), ele de-

${ }^{19}$ HEIDEGGER, Martin. History of the Concept of Time - Prolegomena. Translated by Theodore Kisiel. Bloomigton, Indiana: Indiana University Press, 1992, p. 99. 
senvolve uma fenomenologia da própria correlação, enquanto fenômeno que inclui a ambos.

O que acarretará, portanto, essa redução transcendental, enquanto procedimento metodológico para se alcançar a região especificamente fenomenológica de investigação? Em primeiro lugar a retirada (não necessariamente a negação) da tese transcendental do mundo como horizonte de investigação rigorosa. Em segundo lugar, como sua necessária consequência, a absoluta identificação das esferas de ser da reflexão fenomenológica e do próprio objeto refletido.

O peculiar aspecto da reflexão já é evidente aqui, nominalmente, que o objeto da reflexão, os atos, pertence à mesma esfera de ser que a contemplação do objeto. Reflexão e objeto refletido pertencem ambos a uma e mesma esfera de ser. O objeto, o contemplado, e a contemplação estão realmente incluídos um no outro. O objeto e o meio de apreensão pertencem ao mesmo fluxo de experiência. Essa inclusão real do objeto apreendido na apreensão mesma, na unidade da mesma realidade, é chamada imanência. Imanência aqui tem o sentido da união real do refletido e da reflexão. ${ }^{20}$

A imanência constitui o primeiro resultado positivo da redução transcendental. Com ela chega-se a um campo de investigação (o das puras experiências vividas) em que o mundo transcendente (sempre suscetível de velamentos e enganos) pode tornar-se completamente objetivo, da mesma forma que aconteceu com o processo de ideação proporcionado pela geometria aplicada de Galileu. Com esse novo âmbito científico - mais rigorosamente um âmbito filosófico - foi alcançado o primeiro passo para a construção de uma filosofia rigorosamente científica.

Constitui-se assim uma nova região de ser, cujo caráter absoluto proporciona o terreno firme que o ideal da filosofia como ciência estrita requeria. Pois, diferentemente dos objetos da atitude natural, transcendentes e heterogêneos à consciência, os objetos da atitude fenomenológica, as vivencias puras, são homogêneas ao próprio eu, são, como ele, pura consciência-de; são-lhe, portanto, dados de um modo absoluto, inteiramente patentes, sem sombra de dúvida. ${ }^{21}$

Após alcançar o horizonte transcendental da consciência, com o objetivo primeiro de delinear a região de possíveis conhecimentos universalmente válidos - e aqui podemos perceber o quanto o projeto de Husserl está aparentado com o pensamento kantiano -, resta agora investigar e esclarecer os mecanismos e conteúdos ideativos concernentes a esse fluxo de puras

${ }^{20}$ HEIDEGGER, Martin. History of the Concept of Time - Prolegomena. Translated by Theodore Kisiel. Bloomigton, Indiana: Indiana University Press, 1992, p. 96-97.

${ }^{21}$ RODRÍGUEZ, Ramón. Heidegger y la crisis de la época moderna. Madrid: Síntesis, 2006, p. 39. 
experiências vividas, a fim de obter o conhecimento acerca de suas formas essenciais.

Esse campo singular de meu próprio fluxo de experiência é então submetido a uma segunda redução, a redução eidética. Os atos e seus objetos não são agora estudados como individuações concretas de meu ser concreto, enquanto esse fluxo de experiência. Antes, essa unidade do fluxo de experiência é agora considerada ideativamente. Todo momento que especifica esse fluxo individual como individual é agora suspenso. O que é agora discernido nas experiências vividas concretamente é simplesmente a estrutura pertencente a uma percepção, representação, ou julgamento enquanto tal, indiferentemente se esse julgamento ou essa percepção é minha, indiferentemente se ela toma lugar nesse momento ou nessa constelação concreta ou em outra. Essa dupla redução (a transcendental e a eidética) extrai da individuação concreta e inicialmente dada de um fluxo de experiência o que é chamado o puro campo da consciência, isso é, um campo que não é mais concreto e individual, mas puro. ${ }^{22}$

A princípio, como cada ato da consciência (percepção, representação, julgamento, etc.) apresentará uma forma essencial específica, então cada intencionalidade desses atos constituiria uma ontologia própria. É o momento do desenvolvimento das ontologias regionais. Vê-se como Husserl introduz novamente, em pleno momento antimetafísico da história recente, o conceito de ontologia, mesmo que no plural. Só pode haver ontologias na fenomenologia husserliana, pois ela irá trabalhar com categorias específicas de acordo com o campo de investigação. Nesse sentido, Husserl subordina a ontologia à fenomenologia, determinando o ser a partir do horizonte puro da intencionalidade da consciência. Chegamos, portanto, ao ponto de inflexão do pensamento husserliano, àquilo que determinará sua filosofia como a característica fundamental de seu pensar: a imanência da consciência transcendental apresenta-se como o horizonte absoluto de ser, já que tanto a noesis como o noema manifestam-se exclusivamente no próprio fluxo da consciência.

[...] qualquer coisa objetiva no que é denominada percepção imanente está definida pela mesma espécie de ser que a percepção imanente mesma. Isso implica que o objeto da percepção imanente é absolutamente dado. O fluxo de experiência vivida é, portanto, uma região de ser que constitui uma esfera de posição absoluta, como Husserl diz. [...] Assim, torna-se claro que a esfera da imanência é distinguida por seu modo de dação, que é denominada absoluto. [...] nós agora vemos que a esfera da consciência pura obtida através da redução transcendental e da redução eidética está distinguida pelo caráter de ser absolutamente dado. Então, a pura consciência é, para Husserl, a esfera do ser absoluto. ${ }^{23}$

${ }^{22}$ HEIDEGGER, Martin. History of the Concept of Time - Prolegomena. Translated by Theodore Kisiel. Bloomigton, Indiana: Indiana University Press, 1992, p. 100.

${ }^{23}$ HEIDEGGER, Martin. History of the Concept of Time - Prolegomena. Translated by Theodore Kisiel. Bloomigton, Indiana: Indiana University Press, 1992, p. 100-101. 
Assim, podemos ver como através de suas análises sobre as condições de possibilidades do conhecimento objetivo; sobre a esfera em que esse conhecimento poderia ser dado; sobre a maneira como essa esfera de idealidade poderia ser alcançada; e as principais consequências de seu método fenomenológico, Husserl, além de mostrar as insuficiências que o psicologismo (e o naturalismo) carregava acerca dessas problemáticas, também abre um novo âmbito estritamente filosófico e uma nova perspectiva em relação aos caminhos que a filosofia pode trilhar, influenciando uma gama de pensadores acerca das possibilidades tanto da própria filosofia, como também da ciência empírica enquanto horizonte de conhecimentos universais.

\title{
3 - A Crítica heideggeriana à Fenomenologia de Husserl
}

Heidegger é, sem sombras de dúvida, o nome mais importante do movimento fenomenológico depois de Edmund Husserl. O próprio Husserl, após sua ida para Freiburg e do começo das atividades com seu "assistente", afirma: "A fenomenologia: somos eu e Heidegger". Contudo, as diferenças entre os dois pensadores autorizam-nos dizer que a fenomenologia de Heidegger, além de não ser igual à husserliana, desde o começo se desenvolve em um horizonte de questionamento diferente e cada vez mais se distancia do projeto daquele que é considerado o pai da fenomenologia. Portanto, para uma compreensão mais transparente de como a fenomenologia apresentouse para Heidegger como o autêntico método filosófico, e através do qual seria possível um estabelecimento do lugar e do status da ciência, devem ser levados em consideração os motivos filosóficos que o conduziram a se aproximar de Edmund Husserl e, consequentemente, se envolver com o movimento fenomenológico. Esses motivos, todavia, são-nos indicados pelo próprio Heidegger:

\begin{abstract}
Soube, por diversas indicações, em revistas filosóficas, que a maneira de pensar de Husserl era determinada por Franz Brentano. [...] Das Investigações Lógicas de Husserl esperava um estímulo decisivo com relação às questões suscitadas pela dissertação de Brentano. Porém, era vão meu esforço, porque, somente mais tarde o descobriria, eu as questionava de maneira inadequada. Contudo, a obra de Husserl marcara-me de tal modo, que nos anos subsequentes sempre a li, sem compreender suficientemente o que me fascinava. ${ }^{24}$
\end{abstract}

${ }^{24}$ HEIDEGGER, Martin. Heidegger. (Os Pensadores). São Paulo: Abril Cultural. 1973, p. 495. 
A partir dessas afirmações fica clara a intenção que suscita o interesse de Heidegger pelos escritos de Husserl. Ele considera que através dos escritos husserlianos encontraria as explicações ou indicações "às questões suscitadas pela dissertação de Brentano". Ou seja, Heidegger, em um primeiro momento, não possui um interesse direto pelos escritos de Husserl, mas entra em contato com os mesmos a fim de compreender melhor a postura de Brentano. Isso demonstra o quanto ele, desde o início, já se movimenta em um horizonte bastante definido e distinto daquele que engloba o projeto husserliano, nominalmente, o horizonte metafísico da questão do Ser imposto ao seu pensamento pela leitura da dissertação de Brentano:

O primeiro texto filosófico (die erste philosophische Schrift) através do qual eu trabalhei meu caminho sempre de novo desde 1907 foi a dissertação de Franz Brentano, Do múltiplo significado do ente segundo Aristóteles. Brentano pôs na página-título de sua obra a frase de Aristóteles: tò ón légetai polachós. Traduzo: o ser se manifesta (a saber sob o ponto de vista do ser) de múltiplos modos. Nesta frase se oculta a pergunta determinante do caminho do meu pensamento (die meinen Denkweg bestimmende Frage): qual é a simples e unitária determinação do ser que perpassa todos os múltiplos significados? Esta pergunta suscita o seguinte: que significa Ser. ${ }^{25}$

É precisamente por causa desse "encaminhamento" filosófico através da questão metafísica do Ser que Heidegger posteriormente reconhece a sua "inadequada" maneira de abordar as Investigações Lógicas de Edmund Husserl. Seus horizontes de questionamentos são diferentes e os pressupostos que os conduzem estão direcionados para projetos de naturezas distintas. Enquanto Husserl busca a apoditicidade do conhecimento no horizonte das puras experiências vividas da consciência transcendental - a fim de fundar uma filosofia como ciência rigorosa -, Heidegger busca resgatar a problemática metafísica da tradição filosófica, no qual a questão acerca do Ser impõe sua primazia. O primeiro ponto de ligação entre os dois pensadores, antes de ser a problemática de suas investigações ou o objetivo comum de seus projetos, é a influência decisiva com que Franz Brentano acomete-os, embora a partir de horizontes distintos.

O ponto de partida filosófico de Husserl era Franz Brentano, o autor de Psicologia do ponto de vista empírico. Meu próprio ponto de partida, observa ele, era o mesmo de Franz Brentano, mas não com essa obra de 1874; pelo contrário, era Sobre o múltiplo significado do ente conforme Aristóteles (Freiburg 1862), em que Heidegger aprendeu a ler filosofia. ${ }^{26}$

Isso não significa, entretanto, que Heidegger não encontre na fenomenologia de Husserl elementos válidos para o seu projeto essencialmente metafísico.

\footnotetext{
${ }^{25}$ HEIDEGGER apud SASSI, Vagner. A questão acerca da origem e a apropriação nãoobjetivante da tradição do jovem heidegger. Porto Alegre, 2007, pp. 241-242.

${ }^{26}$ HEIDEGGER apud SASSI, Vagner. A questão acerca da origem e a apropriação nãoobjetivante da tradição do jovem Heidegger. Porto Alegre, 2007, p. 247.
} 
Já nas leituras das Investigações Lógicas, que ele confessa sempre retornar com fascínio e com conhecimento de causa inicialmente desconhecido, Heidegger encontra na noção de intuição categorial um importante elemento para o desenvolvimento de seu pensamento, pois vê ali um fundamento fenomenológico acerca da relação essencial do conhecimento humano com o significado Ser. O homem possui uma noção de ser que não advém nem de processos psíquicos e nem através da reflexão. E já que a significação do ser não advém nem da abstração nem de julgamentos, como alcançar então o horizonte da sua determinação? Tal objetivo deve ser alcançado através da e)poxh/ fenomenológica.

Esse pôr entre parêntese do ente nada retira do ente mesmo, não pretende assumir que o ente não seja. Essa inversão de perspectiva tem antes o sentido de fazer o ser do ente presente. Essa suspensão fenomenológica da tese transcendente tem, antes, a única função de tornar o ente presente em relação ao seu ser. O termo "suspensão" é então sempre mal compreendido quando se pensa que suspendendo a tese da existência e mediante ela, a reflexão fenomenológica simplesmente não tem mais nada a fazer com o ente. Justamente o contrário: em um modo extremo e único, o que realmente está em questão agora é a determinação do ser da própria entidade. ${ }^{27}$

A e)poxh/ mostra-se para Heidegger como um procedimento necessário à determinação do significado do ser. Nesse quesito, o aspecto fundamental é ter a cautela de não considerar o termo técnico "suspensão" como uma eliminação do caráter ontológico dos entes, pois isso impediria o horizonte metafísico do pensamento filosófico e o encaminharia a uma Lógica concernente à Teoria do Conhecimento neokantiana ou à postura psicologista. Todavia, é justamente sobre o alcance da e)poxh/ na atividade fenomenológica que se manifestam as diferenças entre a fenomenologia de Heidegger, de matiz metafísico, e a husserliana, onde a e)poxh/ é vista como um momento interno para se alcançar o verdadeiro campo temático da filosofia rigorosamente científica: a consciência pura.

A apreensão do ser, quer dizer, a pesquisa fenomenológica, visa antes de tudo e necessariamente a cada momento o ente, mas para ser logo decididamente desviada deste ente e reconduzida a seu ser. $\mathrm{O}$ elemento fundamental do método fenomenológico, no sentido da recondução do olhar inquisidor do ente tomado ingenuamente ao ser, nós lhe designamos pela expressão de redução fenomenológica. Nós anexamos por isso, quanto a sua literalidade, a um termo central da fenomenologia husserliana, mas não quanto à relação ela mesma. Para Husserl, a redução fenomenológica, tal como ele elaborou pela primeira vez explicitamente nas Ideen de 1913, é o método destinado a reconduzir o olhar fenomenológico da atitude natural do homem vivente no mundo das coisas e das pessoas à via transcendental

${ }^{27}$ HEIDEGGER, Martin. History of the Concept of Time - Prolegomena. Translated by Theodore Kisiel. Bloomigton, Indiana: Indiana University Press, 1992, p. 99. 
da consciência e a suas vivências noético-noemáticas, nas quais os objetos se constituem enquanto que correlatas da consciência. Para nós, a redução fenomenológica designa a recondução do olhar fenomenológico da apreensão do ente - qualquer que seja sua determinação - à compreensão do ser deste ente (projeto em direção da modalidade de seu ser-descoberto). ${ }^{28}$

Diante disso, podemos afirmar que tanto para Husserl quanto para Heidegger a redução fenomenológica é de capital importância para a investigação filosófica. No entanto, como o projeto de cada um vislumbra um objetivo diferente, a função do processo de redução visa coisas também diferentes. Enquanto para Heidegger ela deve visar alcançar o horizonte do ser que se vela em cada manifestação ôntica, para Husserl a redução deve alcançar os conteúdos transcendentais da relação da consciência com seus objetos, a fim de fundamentar "cientificamente" o conhecimento.

Porém o questionável da fenomenologia aparece, para Heidegger, no instante em que Husserl começa a refletir criticamente sobre o alcance e o sentido da práxis fenomenológica. É o momento em que a fenomenologia se vê a si mesma [...] como a única filosofia capaz de realizar o ideal de uma fundamentação absoluta do conhecimento, mediante a abertura de um campo próprio de investigação: a consciência pura ou transcendental. ${ }^{29}$

$\mathrm{Na}$ fenomenologia husserliana, a consciência transcendental torna-se o campo central da filosofia em dois aspectos diferentes, porém complementares. Em primeiro lugar, porque a consciência transcendental desfruta de uma transparência inacessível à consciência inserida na atitude natural, tornando-se assim o único "sujeito" possível de uma reflexão filosófica que se veja como ciência rigorosa. Em segundo lugar, porque é o fluxo de vivências da própria consciência transcendental que se torna o objeto da investigação filosófica. Assim, embora faça parte daqueles pensadores que reintroduzem o tema de ontologias, toda a filosofia husserliana acaba por girar em torno da ideia de uma consciência reflexivamente pura. Ou seja, o ser em Husserl (que possibilita falar em uma redução eidética) é sempre o ser intencional da consciência, e toma das características desta suas determinações.

Heidegger, porém, questiona esse status da consciência enquanto exclusivo campo de investigação da reflexão fenomenológica. Há, portanto, a necessidade de uma averiguação do que há de implícito nas determinações dessa consciência. Na visão de Heidegger, toda determinação almeja e leva consigo uma determinação de ser. Portanto, os resultados de Husserl levam consigo noções acerca do ser da consciência que não estão bem esclarecidas.

\footnotetext{
${ }^{28}$ HEIDEGGER, Martin. Les problèmes fondamentaux de la phénoménologie. Paris: Éditions Gallimard, 1985, pp. 39-40.

${ }^{29}$ RODRÍGUEZ, Ramón. Heidegger y la crisis de la época moderna. Madrid: Síntesis, 2006, p. 37.
} 
São quatro as principais determinações desse horizonte, e é a partir delas que surgirá a resposta acerca da autenticidade dos resultados na investigação fenomenológica realizada por Husserl.

Consciência é 1) ser imanente; 2) o imanente é o ser absolutamente dado. Essa dação absoluta também é chamada ser absoluto pura e simplesmente. 3) Esse ser, compreendido como dação absoluta, é também absoluto no sentido que nulla re indiget ad existentum (assim a velha definição de substância é adotada): "ele não necessita de res para ser". Res é aqui compreendida no sentido mais estreito de realidade, ser transcendente, isto é, qualquer ente que não é consciência. 4) Ser absoluto nessas duas significações - dado absolutamente e não necessitando de realidade - é ser puro, no sentido de ser a essência, o ser ideal das experiências vividas. [...] Nós devemos perguntar o seguinte sobre essas quatro determinações de ser: Elas são determinações que surgem de um olhar para a coisa mesma? Elas são determinações de ser que são retiradas da consciência e do próprio ente intencionado por esse termo ${ }^{30}$

Heidegger está questionando aqui o próprio caráter fenomenológico das investigações husserlianas, pois, caso essas determinações de ser não tenham surgido de um olhar que esteja voltado para a coisa mesma, ou seja, para a consciência enquanto intencionalidade, então Husserl terá se desviado metodologicamente já no próprio ponto de partida de seu pensamento. $\mathrm{O}$ que significa dizer que a consciência fenomenológica, enquanto fluxo de puras experiências vividas, manifesta uma imanência? Até que ponto essa determinação de ser está voltada para a consciência em si? A imanência enquanto determinação de ser só pôde ser alcançada no momento em que a reflexão - ou seja, a intencionalidade da consciência - voltou-se para outro ato da consciência. Isso quer dizer que tal imanência está referida à relação existente entre os dois atos, mas nada diz acerca do próprio ser intencional da consciência. A intencionalidade enquanto tal, aquilo que caracteriza a própria consciência, continua na obscuridade no que diz respeito ao seu ser.

Por sua vez, pelo fato de que os seus atos se encontram no horizonte da imanência, a consciência é tomada como aquilo que é absolutamente dado. Isso quer dizer que as experiências vividas se exibem original e diretamente, apresentam-se de modo absoluto e, portanto, estão alheias a qualquer tipo de mediação que as exibissem de forma indireta ou simbólica. Elas são absolutamente dadas, e por isso, são absolutamente. Essa segunda determinação do ser da consciência (de ser absolutamente dado e, portanto, ser absoluto), sustenta-se da primeira determinação. Desta forma, ela também se refere aos atos da consciência e não à consciência em seu ser. Além do mais, enquanto a primeira determinação exposta pelas investigações de

${ }^{30}$ HEIDEGGER, Martin. History of the Concept of Time - Prolegomena. Translated by Theodore Kisiel. Bloomigton, Indiana: Indiana University Press, 1992, p. 103. 
Husserl, a de ser imanente, se referiam de alguma forma ao ser dos atos da consciência (enquanto uma relação de ser entre os atos de uma mesma região), essa segunda determinação está ainda mais desviada de um verdadeiro olhar para a coisa mesma. Tal observação crítica se justifica porque a determinação do ser absolutamente dado só pode ser tomada na medida em que uma experiência vivida se torne objeto refletido de um ato que o reflete. Ou seja, não diz respeito ao seu ser, mas simplesmente a um específico modo em que um ato pode apresentar-se a outro. O que é exposto aqui é apenas um ato enquanto possível objeto de reflexão.

A terceira determinação da consciência nas investigações husserlianas também diz respeito ao seu caráter absoluto. No entanto, o significado desse ser absoluto toma outra conotação. Enquanto ser imanente e absolutamente dado, manifesta-se uma autossuficiência da consciência no que diz respeito ao seu próprio ser, isto é, às experiências vividas. Ou seja, à consciência - enquanto experiências imanentemente vividas - nada interessa acerca da existência das coisas. Ela é autossuficiente em seu próprio ser, manifesta-se como um horizonte absoluto fechado em si mesmo, em resumo, manifesta-se como ser absoluto.

Assim, torna-se claro que [...] a consciência considerada em sua "pureza" deve ser tomada como sendo um complexo autossuficiente de ser, um complexo de ser absoluto no qual nada pode penetrar e para fora do qual nada pode soltar-se; para o qual nada é espaço-temporalmente externo e que não pode estar espaço-temporalmente dentro de qualquer complexo; que não pode ser afetado por qualquer coisa física e não pode exercer causa sobre qualquer coisa física - sendo pressuposto que causalidade tem o sentido normal de causalidade pertencendo à Natureza como uma relação de dependência entre realidades. ${ }^{31}$

Ela dispensa qualquer referência ao real, no sentido de coisa material. Isso implica que, enquanto todas as outras coisas que se apresentam a nós mudam e mesmo podem não ser, a consciência manifesta uma continuidade absoluta de ser. Assim, como ser verdadeiramente absoluto, tudo o mais se manifesta como relativamente a ela - todo ser inicialmente considerado transcendental apenas é enquanto remetido à consciência, enquanto ela lhe dar seu caráter de ser.

Então o sentido comumente expressado ao falar de ser é invertido. O ser que é primeiro para nós [o mundo externo] é segundo em si; isto é, ele é o que é, apenas em relação ao primeiro [consciência]. [...] A realidade não é algo em si absoluto, que se torna secundariamente ligado a alguma outra coisa; antes, no sentido absoluto, ela absolutamente não é; ela não tem "essência absoluta"; ela tem a essencialidade de algo que, necessariamente, é apenas

31 HUSSERL, Edmund. Ideas pertaining to a pure phenomenology and to a phenomenological philosophy, 1983, (FALTA LOCAL E EDITORA) p. 112. 
intencional, apenas um objeto da consciência, algo apresentado (Vorstelliges) na maneira peculiar à consciência, algo aparente "enquanto aparente". ${ }^{32}$

A consciência é, enquanto ser absoluto, o pressuposto para qualquer outro ser. Contudo, o fato de que se afirma da consciência que ela seja o ser primeiro a partir do qual todas as outras coisas possam ser consideradas, não determina nada acerca das características de seu próprio ser, apenas institui a mesma como sendo a primeira na ordem da constituição das coisas. Apenas afirma que ela, não dependendo de nenhum outro ser para se constituir, deve ser presumida como condição de possibilidade para se afirmar a constituição objetiva - enquanto ser possível - de todo o resto. Dessa forma, devemos considerar que essa terceira determinação da consciência que se encontra nas investigações fenomenológicas de Husserl não determina a coisa em seu próprio ser, mas apenas em relação à ordem de constituição das coisas.

Já a quarta e última determinação analisada por Heidegger é a que afirma a pureza do ser da consciência. Esta última não passa de uma consequência do caminho percorrido pelas três determinações anteriores, considerando a consciência como ser puro pelo fato de ela não estar vinculada à realidade material. Ou seja, consciência enquanto ser puro significa simplesmente ser não real (material). Seguindo essa linha de argumentação, Heidegger desqualifica as quatro determinações principais da consciência fenomenológica de Husserl. Todas elas são, no máximo, determinações da região da possível investigação, mas não determinações do ser do ente dessa região.

Todas as quatro determinações do ser da região fenomenológica: ser imanente, ser absoluto no sentido de dação absoluta, ser absoluto no sentido do a priori na constituição [das coisas], e puro ser, não são de modo algum retirados da coisa mesma. Antes, na medida em que elas são expostas como determinações do ser da consciência, elas imediatamente qualificam-se como obstáculos no caminho de perguntar sobre o ser deste ente e assim também acerca da elaboração mais clara deste ente mesmo. As determinações de ser [desenvolvidas por Husserl] não são derivadas da consideração do intencional em seu próprio ser, mas na medida em que ela é colocada sob a investigação como apreensora, doadora, constituinte e ideal, tomados como uma essência. É dessas perspectivas, que no primeiro exemplo estão alheias à consciência, que essas determinações do ser são derivadas. ${ }^{33}$

Desta forma, Heidegger pretende demonstrar o não-alinhamento que o pensamento de Husserl manifesta em relação a uma autêntica investigação fenomenológica, isto é, comprometida com o "retorno às coisas mesmas":

32 HUSSERL, Edmund. Ideas pertaining to a pure phenomenology and to a phenomenological philosophy. First Book. Translated by F. Kersten. Dordrecht, The Netherlands: Kluwer Academic Publishers, 1983, pp. 112-113.

${ }^{33}$ HEIDEGGER, Martin. History of the Concept of Time - Prolegomena. Translated by Theodore Kisiel. Bloomigton, Indiana: Indiana University Press, 1992, p. 106. 
A questão primária de Husserl não está simplesmente preocupada com o caráter de ser da consciência. Antes, ele é guiado pela preocupação seguinte: Como pode a consciência tornar-se o objeto possível de uma ciência absoluta? A preocupação primária que o guia é a ideia de uma ciência absoluta. Essa ideia, de que a consciência tem de ser a região para uma ciência absoluta, não é algo simplesmente inventado; ela é a ideia que ocupou a filosofia moderna desde Descartes. A elaboração da consciência pura como o campo temático da fenomenologia não é derivada fenomenologicamente por um retorno às coisas mesmas, mas por um retorno a uma tradicional ideia de filosofia. ${ }^{34}$

Este é o principal ponto de bifurcação entre os pensamentos de Heidegger e de Husserl. Apesar de reconhecer a importância que as análises husserlianas possuem, principalmente em relação à intuição categorial e à intencionalidade da consciência, Heidegger percebe que o estabelecimento da consciência transcendental como centro da reflexão filosófica é uma decisão automática que não está motivada fenomenologicamente, mas sim pela permanência de Husserl à visão moderna de uma consciência pura como o elemento fundador e autotransparente do conhecimento ${ }^{35}$. Essa visão, além do mais, está vinculada a um projeto bastante específico - o projeto cartesiano de fundamentar filosoficamente o conhecimento científico. Um dos critérios que Heidegger levará em consideração para efetuar essa crítica é a diferença entre o conhecimento direto (actus exercitus) e o conhecimento reflexivo (actus signatus), ou seja, entre a vivência da consciência e a reflexão da consciência sobre sua vivência. Com isso, ficam colocadas em questão tanto a redução transcendental (onde a consciência é tomada antes de tudo como um sujeito cognoscitivo - ou como Heidegger diz, apreensor), como a redução eidética (onde as próprias vivências da consciência transcendental apresentam-se como objetos absolutamente dados para uma autêntica observação de essências). Ambas vão mostrar suas insuficiências diante da primazia dos actus exerciti.

[...] precisamente a distinção entre os actus exerciti e os actus signati levanta um problema que se resumiria para Husserl no problema do mundo da vida. Se nem todo o actus exercitus pode transformar-se em actus signatus ou ao menos só transformar-se parcialmente; se o esforço de reflexão não chega a esgotar constantemente o conhecimento direto e as vivências concretas; se o esforço de reflexão chega mesmo a ocultar dimensões dos actus exerciti; então, impõe-se a seguinte questão: pode a redução transcendental

\footnotetext{
${ }^{34}$ HEIDEGGER, Martin. History of the Concept of Time - Prolegomena. Translated by Theodore Kisiel. Bloomigton, Indiana: Indiana University Press, 1992, p. 107.

${ }^{35} \mathrm{O}$ afastamento de Heidegger em relação às filosofias da consciência não é, absolutamente, um ponto de consenso entre os comentadores. Por exemplo, Hebeche, em Heidegger $e$ os indícios formais (2001), afirma que Heidegger, apesar de abandonar um solipsismo metodológico encontrado, por exemplo, na filosofia de Husserl, ainda se vale de um método monocêntrico, onde o ponto de convergência de suas reflexões se encontra no constructo Dasein.
} 
ao ego atingir a exigida radicalidade? É possível que a reflexão e redução transcendental recuperem radicalmente o mundo da vida na consciência transcendental ${ }^{36}$

Para Heidegger, a resposta a essas perguntas teria de ser negativa, pois a reflexão possui uma dimensão diferente da vivência direta da vida fática. A atividade de um eu reflexivo possui como condição de possibilidade o distanciamento em relação ao "objeto", ela será sempre um segundo momento, enquanto que na vivência da vida fática o que se apresenta é uma relação direta, demonstrando na postura husserliana uma inadequação intrínseca da abordagem acerca do campo de investigação. Assim, tomando em consideração a existência desse pressuposto de Husserl não demonstrado fenomenologicamente, ou seja, de que a consciência (por pensar a si mesmo de modo autotransparente) seria uma região de ser absoluta e constitutiva de tudo o mais, Heidegger demonstra o quanto ele permanece vinculado às filosofias da subjetividade de cunho epistemológico que predominaram no pensamento filosófico desde Descartes.

Diante de tudo isso, qual será, portanto, a solução encontrada por Heidegger para salvaguardar o que ele considera as conquistas autênticas - intuição categorial e intencionalidade - alcançadas pela fenomenologia? Fazer uma crítica aos pressupostos cartesianos ocultos no pensamento de Husserl, pois, no final das contas, foram esses que o impossibilitaram de chegar ao autêntico conteúdo da investigação fenomenológica. Um exemplo claro disto é a aceitação por parte de Husserl da consciência pura como aquele absoluto ser que instaura objetivamente a possibilidade de todas as outras coisas, ou seja, a redução cartesiana que encontrará no ego sum o horizonte puro e fundamentador de todo possível conhecimento.

A equivalência entre Descartes e a fenomenologia (husserliana) pode ser desdobrada em duas direções; ou Descartes é um fenomenólogo porque antecipa Husserl, ou a fenomenologia husserliana não é completamente fenomenológica, porque permanece atada a posições cartesianas que não foram criticadas, ou mesmo reconhecidas. Muito cedo, Heidegger decide tomar a segunda direção. A distância que ele toma em relação à interpretação husserliana de fenomenologia será levada por meio de uma crítica das pressuposições cartesianas que se oculta nesse último. Descartes receberá uma crítica, mas uma crítica que é primeiramente endereçada mais a Husserl, que é agora considerado como sendo menos que um fenomenólogo em virtude de sua herança cartesiana. Assim, Descartes aparece como o motivo não-fenomenológico de Husserl. ${ }^{37}$

${ }^{36}$ STEIN, Ernildo. A questão do método na filosofia: um estudo do modelo heideggeriano. $3^{\mathrm{a}}$ ed. Porto Alegre: Movimento 1983, p. 45.

${ }^{37}$ MARION, Jean-Luc. Heidegger and Descartes. In: Critical Heidegger. MACANN, Christopher (org), Londres, Routeledge, 1996, pp. 70-71. 
São as vinculações não declaradas com Descartes que devem ser afastadas da investigação fenomenológica, pois elas impediram Husserl de encontrar o autêntico conteúdo da filosofia e, consequentemente, também determinar o valor e o lugar da ciência no conjunto do pensamento. O objetivo para Heidegger é, portanto, limpar o que há de obstáculo nessa fase inicial da fenomenologia. E como ele irá fazer essa limpeza? Através do desenvolvimento de sua própria visão do que seja a fenomenologia; da redução fenomenológica que visa, antes de tudo, o ser dos entes; e substituindo a consciência transcendental de caráter fundacionista pelo modo de ser do Dasein, abrindo caminho para a analítica existencial e todas as suas consequências.

Endereço do Autor:

Rua Almir Azevedo 76, apto 103A

50740-610 - Recife - PE

e-mail: jfabinhoa@gmail.com 
